\title{
Antibacterial activities of moringa olifiera freeze dried extract on staphylococcus aureus
}

\author{
Wulan Angestia, ${ }^{1,2}$ Valendriyani Ningrum, ${ }^{1}$ Tai L. Lee, ${ }^{2}$ \\ Shih-Chieh Lee, ${ }^{3}$ Abu Bakar ${ }^{3,4 *}$
}

\section{Abstract}

Objective: The aim of this study is to determine the antibacterial activities of M. oleifera freeze dried extract on Staphylococcus aureus. Material and Methods: The antibacterial activities using two methods, microdilution method and agar diffusion method. The minimum inhibitory concentration is determined. The measurement of absorbance in microdilution method using a spectrophotometer at length wave $590 \mathrm{~nm}$. The inhibition zone is measured using scalimeter.
Results: The results showed both microdilution method and agar diffusion method present the inhibition activity of M. oleifera freeze dried extract on staphylococcus aureus.

Conclusion: The finding confirmed M. oleifera freeze dried extract as the promising antibacterial natural agent, particularly on inhibiting $S$. aureus strain.
'Department of Pediatric Dentistry, Faculty of Dentistry, Baiturrahmah University, Kuranji, Padang, Indonesia

${ }^{2}$ Department of Biomedical Science, Da-Yeh University, Dacun, Changhua, Taiwan

${ }^{3}$ Department of Food Science and Biotechnology, Da-Yeh University, Dacun, Changhua, Taiwan

${ }^{4}$ Department of Oral Medicine, School of Dentistry, Baiturrahmah University, Kuranji, Padang, Indonesia

"Correspondence to: Abu Bakar, Department of Food Science and Biotechnology, Da-Yeh University., Dacun, Changhua, Taiwan, Republic of China. Department of Oral Medicine, School of Dentistry, Baiturrahmah University, Kuranji, Padang, Indonesia abuba.mmed@gmail.com

\section{Received: 1 April 2020}

Revised: 3 June 2020

Accepted: 2 November 2020

Available Online: 1 December 2020

Keywords: Antibacterial, freeze dried, Staphylococcus aureus

Cite this Article: Angestia W, Ningrum V, Lee T, Lee S, Bakar A. 2020. Antibacterial activities of moringa olifiera freeze dried extract on staphylococcus aureus. Journal of Dentomaxillofacial Science 5(3): 154-157. D0I: 10.15562/jdmfs.v5i3.1043

\section{Introduction}

Moringa oleifera is derived from the family Moringaceae. M. oleifera is rich in nutrition due to its variety of important constituents present in its leaves, pods and seeds. ${ }^{1} \mathrm{M}$. oleifera is relatively grow in both tropical and subtropical areas of the world with a temperature between $25-35^{\circ} \mathrm{C}$. It needs sandy or loamy soil with a little acidic to a little alkaline $\mathrm{pH}$ and a remaining rainfall of 250-3000 mm. ${ }^{1,2}$ M. oleifera leaves, pods and seeds possess some phytochemicals like tannins, sterols, saponins, trepenoids, phenolics, alkaloids and flavanoids like quercitin, isoquercitin, kaemfericitin, isothiocyanates and glycoside compounds are present. ${ }^{1}$

Moringa oleifera and its constituents have been used for multiple medicinal properties such antioxidant activity, ${ }^{3,4}$ anti-inflammatory activity, ${ }^{4}$ antimicrobial activities, ${ }^{5-9}$ blood pressure lowering effect, ${ }^{10,11}$ antitumor, ${ }^{12}$ anticancer, ${ }^{13-15}$ cholesterol lowering effect, ${ }^{16}$ antidiabetic, ${ }^{17}$ and antiobesity. ${ }^{18}$ The antibacterial properties of M.oleifera have been tested to some microbiomes like escheria coli, staphylococcus aureus, ${ }^{7,8}$ streptococcus mutans, candida albicans, ${ }^{19}$ streptococcus pyogenes, bacillus subtilis, corynebacterium pyogenes, klebsiella pneumoniae, salmonella typhi and pseudomonas aeruginosa. ${ }^{20}$ Among those antibacterial methods, ethanolic and aqueous extract were commonly used in the experimental procedures. ${ }^{5,8,9,19}$

Previous study compared the different ways including freeze dried extract of food preparation and preservation which may affect significantly the concentration and availability of minerals, vitamins and other essential compounds in food. State of the art, the aim of this study is to determine the antibacterial activities of moringa oleifera freeze dried extract on staphylococcus aureus using two antibacterial test methods (microdilution method and agar diffusion method).

\section{Material and Methods Plant extraction}

Plant of M. oleifera were placed in container flask and added with ethanol with comparison 1;1 for $72 \mathrm{~h}$, the extracts were filtrated with Whatman filter paper and then evaporated $1 \mathrm{ml}$ to obtain weigh the dried extract $\mathrm{I}$ in $1 \mathrm{~mL}$. Then adjust concentration from $500 \mu \mathrm{g} / \mathrm{mL}$ to $0.48 \mu \mathrm{g} / \mathrm{mL}$.

\section{Determining minimum inhibitory concentration}

Prepare the Ethanol extract of A. vera and M. oleifera with variuos concentration were used are $3.9 \mu \mathrm{g} /$ $\mathrm{mL}, 1.9 \mu \mathrm{g} / \mathrm{mL}, 0.9 \mu \mathrm{g} / \mathrm{mL}, 0.48 \mu \mathrm{g} / \mathrm{mL})$. Test minimun inhibitor concentration used microdillution using 96 well, each well contain $1.5 \mu \mathrm{L}$ members of cells, $30 \mu \mathrm{L}$ extract plant and $150 \mu \mathrm{L}$ medium broth and then incubated for $48 \mathrm{~h}$. Ic50 determined using online tools from link https://www.aatbio.com/ tools/ic50-calculator.

Antibacterial experiment; microdilution method; bacteria are cultured on agar nutrient media (NA) at $37^{\circ} \mathrm{C}$ for 24 hours. The bacterial 
suspension was done by taking bacterial culture and dissolved in saline solution $(0.9 \% \mathrm{NaCl})$ aseptically. Suspension turbidity level compared to the $0.5 \mathrm{McFarland}$ standard visually and measurement of absorbance with using a spectrophotometer at length wave $590 \mathrm{~nm}$, the absorbance range was allowance is $0.08-0.13$ which is equivalent to $1-2 \times$ $108 \mathrm{CFU} / \mathrm{mL}$ (clinical and Laboratory Standards Institute, 2009) for dilution testing. Then pipetted as much as $100 \mu \mathrm{l}$ and dilution media were added (nutrient broth) up to $10 \mathrm{ml}$ so that it was obtained microbial suspension with a number of colonies 1-2 × $106 \mathrm{CFU} \mathrm{/} \mathrm{ml.} \mathrm{This} \mathrm{bacterial} \mathrm{suspension}$ which is then used to test the activity, and must be used no more than 30 minutes after manufacture.

Agar diffusion method; the antibacterial activity of M. oleifera samples used paper disc diffusion method. The liquid broth was obtained by using following procedure. $3.9 \mathrm{~g}$ Nutrient Broth (NB) was added by $300 \mathrm{~mL}$ distilled water and mixed with $4.5 \mathrm{~g}$ Nutrient Agar. The mixing solution was liquefied in autoclave for 20 minutes. Each $15 \mathrm{ml}$ mixing solution was positioned in petri dish. The petri dishes were left in the UV light for 24 hours.

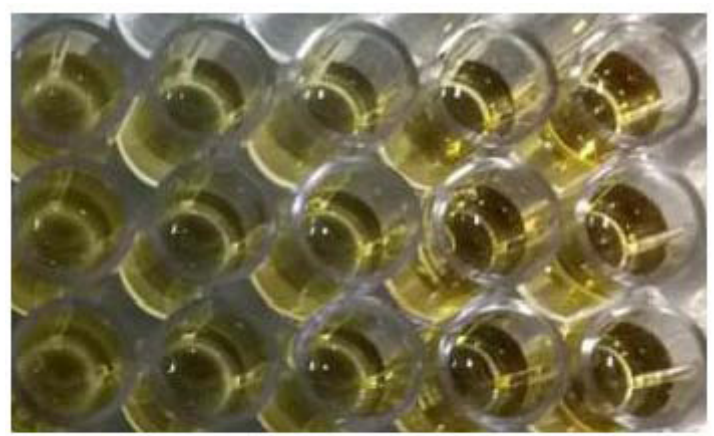

Figure 1 Antibacterial test of moringa oliefera on staphylococcus aureus (96 well plate) first well is medium + bacteria, next well drug with low doses $(0.5)$ to high doses (3.9). Last well is medium
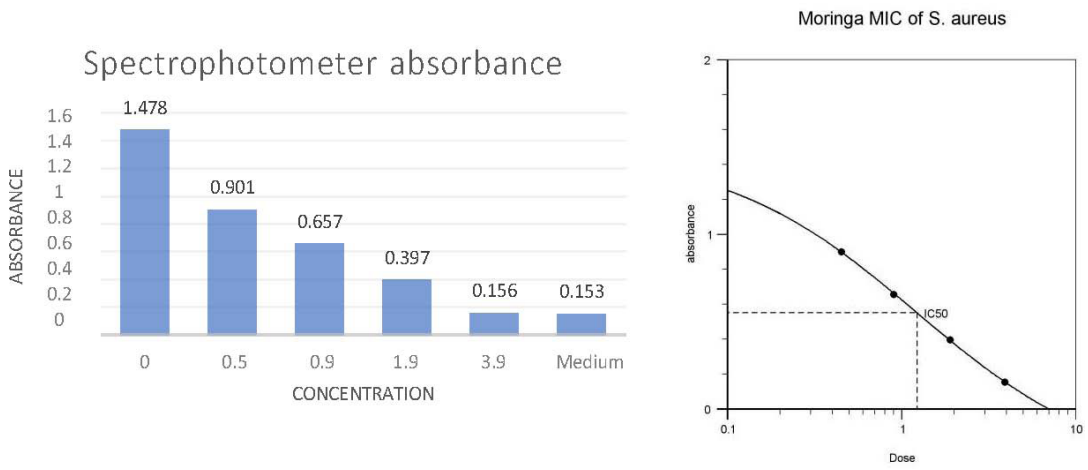

Figure 2 Minimun inhibitory concentration (MIC) of Moringa oleifera on staphylococcus aureus
The bacteria pathogen strain was spread over the surface of agar plates. Sterilized filter paper discs of $6 \mathrm{~mm}$ diameter (paper Whatman ${ }^{\oplus} \# 4$ ) were saturated with $50 \mu$ l of different concentration (25, $50,75,100 \mathrm{mg} / \mathrm{mL}$ ) of green tea samples. The saturated discs were then placed in the middle of plates and incubated for $24 \mathrm{~h}$ at $27^{\circ} \mathrm{C}$. Negative control was prepared with distilled water and commercial antibiotic (tetracyclin) was used as positive control. The diameter of each inhibitory zone was measured (scalimeter).

\section{Results}

\section{Antibacterial results (microdilution method)}

Figure 1 Microdilution method of antibacterial activities of M. oleifera freeze dried extract on staphylococcus aureus. Figure 2 shows since the concentration of $0,5 \mu \mathrm{g} / \mathrm{ml}$ has antibacterial activities of M. oleifera, however the MIC present the IC50 on dose $>1 \mu \mathrm{g} / \mathrm{ml}$. The results confirmed M. oleifera has an antibacterial activity. Figure 3 also presents the inhibition to be better in the higher concentration. The inhibition of the concentration $0,9 \mu \mathrm{g} / \mathrm{ml}$ is higher than the concentration $0.5 \mu \mathrm{g} / \mathrm{ml}$. It also presents in the concentration $1.9 \mu \mathrm{g} / \mathrm{ml}$ and $3.9 \mu \mathrm{g} / \mathrm{ml}$ compared to the lower concentration. It was surprisingly report, because in the concentration 3.9, the absorbance value is identic to the medium absorbance value. It's finding can determine the bactericidal activity of $\mathrm{M}$. oleifera freeze dried extract. This finding supports the previous study of M. oleifera using ethanolic extract can kill the growth of the bacterial isolates completely. ${ }^{21}$

\section{Antibacterial results (agar diffusion method)}

The results of microdilution method are strengthened by the results of agar diffusion method. In the concentration $3.9 \mathrm{mg} / \mathrm{ml}$, M. oleifera freeze dried extract has the mean of inhibition zone $17.1+$ $0.3 \mathrm{~mm}$ and in the concentration $7.8 \mathrm{mg} / \mathrm{ml}$ has the mean of inhibition zone $18.85+0.05 \mathrm{~mm}$ and in the concentration $16.6 \mathrm{mg} / \mathrm{ml}$ has the mean of inhibition zone $20.55+0.25 \mathrm{~mm}$. The results indicated M.oleifera freeze dried extract has moderate to strong effect in inhibiting staphylococcus aureus strain. The finding corroborates previous studies which reported the antibacterial activities of M. oleifera by various extract methods has antibacterial activities on Staphylococcus aureus. .,7,8,19,20 $^{2}$

\section{Discussion}

M.oleifera possess some phytoconstituents saponins, tannins, phenols alkaloids. ${ }^{9,21}$ The constituents 

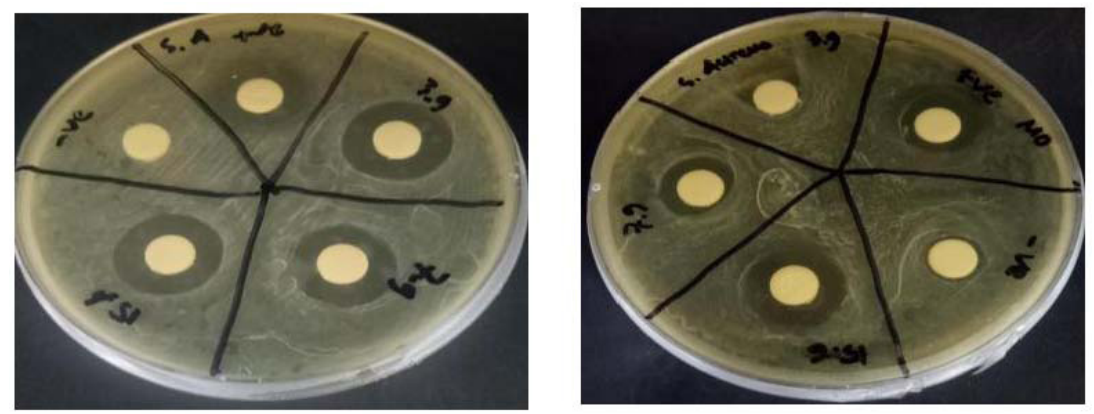

Figure 3 Antibacterial activity of M. oleifera freeze dried extract on staphylococcus aureus (agar diffusion method)

are reported to justification for the action of antimicrobial activity. ${ }^{22,23}$ Saponins played the role to inhibit bacterial growth under cultural condition. Increase of definite action of phosphofructokinase (PFK) and isocitrate dehydrogenase (ICDH) was equivalent with stress response and feedback to pathogenic attack of several bacteria. ${ }^{24}$ One constituent, tannins, has been tested to inhibit Staphylococcus aureus. ${ }^{25}$ The antibacterial mechanisms of tannins through 3 ways; (i) the astringent property that can encourage complexity, many microbial can be inhibited when exposed with tannins, (ii) it's activity on the bacterial membrane, and (iii) complexation of metal ions of tannins which may become toxicity. ${ }^{26}$

The bacteria activity of M. oleifera freeze drying extract has proven, in this study showed Moringa oleifera freeze drying extract could inhibit activity of Staphylococcus aureus. Previous study reported M. oleifera seed extract has inhibitory effects on growth, survival, and cell permeability of several pathological bacterial and also reported to contain active pterygospermin antibiotics that have strong antibacterial and fungicidal effects. Deoxyniazimisin aglycone isolated from the chloroform fraction of ethanol extract of M. oleifera root bark is known as an antibacterial and antifungal activity. ${ }^{27}$

S. aureus is one the most common bacterial infections in humans and are the causative agents of multiple human infections, including bacteremia, infective endocarditis, skin and soft tissue infections. S. aureus becomes resistant to more and more antibiotics, many attempts have been made to find other ways to treat infections. ${ }^{28}$ Recently study showed Moringa oleifera as the strong antibacterial, this study showed Moringa oleifera with low concentration effectivly inhibited staphylococcus growth.

In general, to determine the antibacterial activity screening and evaluating methods, several bioassays such as diffusion and dilution methods are well known and commonly used. This study used two of methods, agar-diffusion and microdilution methods and the results significantly inhibit $S$. aureus growth in low concentration. Using combination methods between diffusion and dilution methods could result the significant concentration of antibacterial activity. The diffusion method was appropriate only as a preliminary screening test prior to quantitative MIC determination and broth microdilution as the MIC values determined by antibacterial activity of plant as a fast screening method for MIC determination. Several previous study determined MIC and antibacterial activity also used combination methods (diffusion and dilution) and the it is for activity antibacterial some of methods used diffusion methods. ${ }^{29}$

\section{Conclusion}

The study reported promising inhibitory activities of M. oleifera freeze drying extract on Staphylococcus aureus. The antibacterial activities have been showed in the low concentration and presented moderate to strong effect. Future studies may compare the antibacterial activities between aqueous extract, ethanol extract and freeze-dried extract.

\section{Acknowledgment}

Special thanks to Professor Tai Lin Lee's Lab to conduct the experiment procedure.

\section{Conflict of Interest}

The authors report no conflict of interest.

\section{References}

1. Gopalakrishnan L, Doriya K, Kumar DS. Moringa oleifera: a review on nutritive importance and its medicinal application. Food Sci Hum Wellness 2016;2: 49-56.

2. Thurber MD, Fahey JW. Adoption of moringa oleifera to combat under-nutrition viewed through the lens of the "diffusion of innovations" theory. Ecol Food Nutr 2009;48: 212-225.

3. Inbathamizh L, Padmini E. Effect of geographical properties on the phytochemical composition and antioxidant potential of Moringa oleifera flowers. Bio Med Rx 2013;1: 239-247.

4. Alhakmani F, Kumar S, Khan SA. Estimation of total phenolic content, in-vitro antioxidant and anti-inflammatory activity of flowers of Moringa oleifera. Asian Pac J Trop Biomed 2013;3: 623-627.

5. Vieira GHF, Mourão JA, Ângelo ÂM, et al. Antibacterial effect (in vitro) of moringa oleifera and annona muricata against gram positive and gram-negative bacteria. Rev Inst Med Trop Sao Paulo 2010;52: 129-132.

6. Nepolean P, Anitha J, Renitta RE. Isolation, analysis and identification of phytochemicals of antimicrobial activity of Moringa oleifera Lamk. Current Biotica 2009;3: 33-39.

7. Moyo. Antimicrobial activities of moringa oleifera lam leaf extracts. African J Biotechnol 2012;11: 2797-2802. 
8. Peixoto JRO, Silva GC, Costa RA, et al. In vitro antibacterial effect of aqueous and ethanolic moringa leaf extracts. Asian Pac J Trop Med 2011;4: 201-204.

9. Doughari JH, Pukuma MS, De N. Antibacterial effects of balanites aegyptiaca L. Drel. and Moringa oleifera Lam. on Salmonella typhi. African J Biotechnol 2007;6: 2212-2215.

10. Faizi S, Siddiqui BS, Saleem R, et al. Fully acetylated carbamate and hypotensive thiocarbamate glycosides from Moringa oleifera. Phytochem 1995;38: 957-663.

11. Faizi S, Siddiqui BS, Saleem R, et al. Hypotensive constituents from the pods of Moringa oleifera. Planta Med 1998;64: 225-228.

12. Guevara AP, Vargas C, Sakurai H, et al. An antitumor promoter from Moringa oleifera Lam. Mutat Res - Genet Toxicol Environ Mutagen 1999;440: 181-188.

13. Suphachai C. Antioxidant and anticancer activities of moringa oleifera leaves. J Med Plants Res 2014;8: 318-325.

14. Al-Asmari AK, Albalawi SM, Athar MT, et al. Moringa oleifera as an anti-cancer agent against breast and colorectal cancer cell lines. PLoS One 2015;10: 1-14.

15. Khor KZ, Lim V, Moses EJ, et al. The in vitro and in vivo anticancer properties of moringa oleifera. Evidence-based Complement Altern Med 2018;2018: 1-14.

16. Ghasi S, Nwobodo E, Ofili JO. Hypocholesterolemic effects of crude extract of leaf of Moringa oleifera Lam in high-fat diet fed wistar rats. J Ethnopharmacol 2000;69: 21-25.

17. Villarruel-López A, López-de LMDA, Vázquez-Paulino $\mathrm{OD}$, et al. Effect of moringa oleifera consumption on diabetic rats. BMC Complement Altern Med. 2018;18: 1-10.

18. Metwally FM, Rashad HM, Ahmed HH, et al. Molecular mechanisms of the anti-obesity potential effect of Moringa oleifera in the experimental model. Asian Pac J Trop Biomed 2017;7: 214-221.

19. Elgamily H, Moussa A, Elboraey A, et al. Microbiological assessment of moringa oleifera extracts and its incorporation in novel dental remedies against some oral pathogens. Maced J Med Sci 2016;4: 585-590

20. Auwal M, Tijjani A, Sadiq M, et al. Antibacterial and haematological activity of Moringa oleifera aqueous seed extract in Wistar albino rats. Sokoto J Vet Sci 2013;11: 28-37.
21. Abubakar I, Usman A. Phytochemical and antibacterial investigations of moringa (moringa oleifera) leaf extract on selected bacterial pathogens. J Microbiol Antimicrob 2016;8: 28-33.

22. Van-Der-Watt E, Pretorius JC. Purification and identification of active antibacterial components in carpobrotus edulis L. J Ethnopharmacol 2001;76: 87-91.

23. Clark AM, El-Feraly AS, Li W -S. Antimicrobial activity of phenolic constituents of magnolia grandiflora L. J Pharm Sci 1981;70: 951-952.

24. Mandal P, Sinha Babu SP, Mandal NC. Antimicrobial activity of saponins from Acacia auriculiformis. Fitoterapia 2005;76: 462-465.

25. Akiyama H. Antibacterial action of several tannins against staphylococcus aureus. J Antimicrob Chemother 2001;48: 487-491.

26. Chung KT, Wong TY, Wei CI, et al. Tannins and human health: a review. Crit Rev Food Sci Nutr 1998;38: 421-464.

27. Kou X, Li B, Olayanju JB, et al. Nutraceutical or pharmacological potential of moringa oleifera lam. Nutr 2018;10: 343-345.

28. Hamudeng AM, Serliawati. Effectiveness of antibacterial extract of coriander seeds (coriandrum sativum L.) against staphylococcus aureus. J Dentomaxillofac Sci 2019;4: 71-74.

29. Klancnik A, Piskernik S, Jersek B, Mozina SS. Evaluation of diffusion and dilution methods to determine the antibacterial activity of plant extracts. J Microbiol Methods. 2010;81: 121-126.

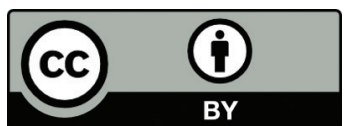

This work is licensed under a Creative Commons Attribution 